\title{
AUDIOMETRIC ASSESSMENT IN POST COVID-19 PATIENTS: A CROSS-SECTIONAL STUDY IN A TERTIARY CARE HOSPITAL OF KARACHI - PAKISTAN
}

\author{
Shanila Feroz, Kausar Mahmood, Iqbal Hussain Udaipurwala*, Syeda Zain, Mahveen Iqbal, Muhammad Abdul Azeem \\ United Medical \& Dental College, Creek General Hospital, Karachi Pakistan, *Bahria University Medical \& Dental College, Karachi Pakistan
}

\section{ABSTRACT}

Objective: To assess audiometry investigations in patients having complaint of tinnitus, vertigo or hearing impairment after recovery from COVID-19 disease, having no external or middle ear diseases.

Study Design: Cross-sectional study.

Place and Duration of Study: United Medical and Dental College, Creek General hospital, Korangi, Karachi Pakistan, from March to May 2021.

Methodology: A total of 60 patients were included in this study who had recovered from the primary COVID-19 infection and reported with the complaints of tinnitus, vertigo and hearing loss. Pure tone audiogram was assessed for sensorineural deafness, its severity and frequencies affected. Pearson Chi square test was used to see the relation of symptoms with severity of hearing loss.

Results: There were $42(70 \%)$ males and 18 (30\%) female patients with age range from 18-50 years with mean age of $28.4 \pm$ 8.1 years. Tinnitus was the most common complaint (83.3\%) followed by hearing loss (28.3\%) and vertigo (23.3\%) patients. None of the patients with complaint of hearing loss had normal pure tone audiogram in either right or left ear $(p=0.000)$. Patients with all the three complaints had more hearing impairment where majority had moderate or severe hearing loss $(p=0.000)$. All patients with isolated complaint of vertigo (9 patients) had normal audiogram in both ears $(p=0.000)$.

Conclusion: Auditory and vestibular system involvement in reasonably common in COVID-19 patients. Tinnitus is the most frequent symptom and it should be investigated with full audiological investigations.

Keywords: Hearing loss, coronavirus, COVID-19, tinnitus, vertigo, Deafness.

How to Cite This Article: Shanila F, Kausar M, Udaipurwala IH, Zain S, Mahveen I, Azeem MA. Audiometric Assessment in Post COVID-19 Patients: A Cross-Sectional Study in a Tertiary Care Hospital of Karachi-Pakistan. Pak Armed Forces Med J 2021; 71 (Suppl-3): S479-483 Doi: https://doi.org/10.51253/pafmj.v1i1.7916

This is an Open Access article distributed under the terms of the Creative Commons Attribution License (https://creativecommons.org/licenses/by-nc/4.0/), which permits unrestricted use, distribution, and reproduction in any medium, provided the original work is properly cited.

\section{INTRODUCTION}

To date Corona Virus 2019 (COVID-19) has affected in more than 210 countries. Pakistan is one among them and is now facing the intense fourth wave of this disease. Even though, vaccines are now available globally along with public education, cases of COVID-19 are increasing leading to health emergency in many countries. Maximum patients infested with COVID-19 have mild to moderate respiratory tract infection, for some days and mostly recover without any particular treatment but many studies have reported extra pulmonary manifestations with multiple organ involvement.1,2 The symptoms relatedwith the peripheral nervous system involved by the disease may include anosmia, hyposmia, visual function deficits and neuralgia. ${ }^{3}$ While few studies mentioned tinnitus, vertigo and hearing loss as an initial presenting symptom or sometimes late sequel of COVID-19 infection. ${ }^{4,5}$

According to UK National Institute for Health and Care Excellence (NICE) there are three phases of COVID-19: (i) acute phase, lasting for upto 4 weeks (ii) second phase lasting from 4-12 weeks and postCOVID syndrome, ongoing from week 12 to on-

Correspondence: Dr. Shanila Feroz, ENT - Head \& Neck Surgery United Medical \& Dental College, Karachi, Pakistan. wards. These two last phase is commonly classified as 'long COVID'. The main complaints of this long COVID embrace tinnitus, dizziness and earache. ${ }^{6}$ There is available data which shows that certain bacterial and viral infections can lead to hearing loss. Viruses which are well known for sensory-neural hearing loss include cytomegalo virus and rubella. ${ }^{7}$ Corona-virus is known to be associated with Guillain -Barré syndrome which can cause auditory neuropathy. ${ }^{8}$ Certain researches also proved that corona viruses have neurotropic and neuro-invasive properties, but the mechanism of inner ear or vestibulecochlear nerve involvement leading to hearing loss and vertigo is still unknown. ${ }^{9}$ Only few studies are published till now on association of COVID-19 with neuroauditory dysfunction. One popular study published recently where asymptomatic COVID- 19 positive patients were compared with normal individuals of similar age and gender, having no auditory complaints. It depicts that mild sensorineural deafness is present at high frequency with suggestion of damage to the outer hair cells of the cochlea. ${ }^{10}$ Conductive deafness in a PCR positive COVID-19 patient has been found with middle ear fluid effusion as a result of ascending nasopharyngeal infection or Eustachian tube dysfunction. ${ }^{5}$ The question is how frequently corona virus is affecting auditory system and 
patients who are getting infected with corona virus will experience hearing issues permanently or their hearing will recover after certain period of time. And if recovery of hearing is expected then when and will it be it will be complete recovery of hearing or partial.

The objective of conducting this study is to assess and compare puretone audiogram in patients complaining of tinnitus, vertigo or hearing loss after recovering from the COVID-19 infection and having no external or middle eardisease.

\section{METHODOLOGY}

This cross-sectional study was carried out in the Audiology unit of the department of Otolaryngology -Head and Neck Surgery, Creek General Hospital, Karachi, from March to May 2021. The Institutional Review Board of United Medical and Dental College, Creek General Hospital has approved the study. Written and informed consent was taken from the each patient included in this study and complete secrecy was maintained regarding personal information.

Inclusion Criteria: The inclusion criteria for the study was those post COVID-19 patients who have complaints of tinnitus, vertigo or hearing loss after recovery from the corona disease. These patients were asymptomatic for COVID-19 infection after 14 days of quarantine period and confirmed by repeated nasopharyngeal swab testing. The patients included in this study were of the ages between 18-50 years so as to exclude age-related deafness and who had normal otoscopic examination findings with an intact tympanic mem-brane bilaterally and type- A tympanogram were included in this study.

Exclusion Criteria: The exclusion criteria were patients having any external or middle ear disease causing conductive deafness, previous history of any external or middle ear disease, any surgery on ear and any history of sensori-neural deafness prior to COVID-19 infection. Patients who had a history of deafness due to any cause or vertigo and those who had a history of migraine, Meniere's disease, stroke, hypertension and brain tumor were also excluded from the study.

Each patient who was agreed to participate in the study was assessed using semi-structured proforma, comprising of 4 main parts. In first part demographic data was included, 2nd part included history related to audio-neurological symptoms, 3rd part comprised of clinical examination and 4th part consists of audiology related investigations.

Pure tone audiogram (PTA) threshold were used to evaluate the auditory function. Thresholds for air conduction were recorded from $250-8000 \mathrm{~Hz}$ frequencies while thresholds for bone conduction were documented 250-4000 Hz frequencies. Hearing loss was classified into groups as; normal hearing $\leq 25 \mathrm{~dB}$, mild $=26-40 \mathrm{~dB}$, moderate $=41-70 \mathrm{~dB}$ and severe $\geq 70 \mathrm{~dB}$. Tympanometry was also done in all the patients to exclude middle ear disease and patients with normal type A tympanogram were included. All the data was recorded and analysed through SPSS-23. Frequencies of both independent and dependent variables were measured while Pearson's Chi square test was used to compare the patients with different symptoms and audiogram findings in right and left ear.

\section{RESULTS}

In this study, a total of 60 patients were included, subsequent to strictly assessing all the inclusion and exclusion criteria. There were $42(70 \%)$ males and $18(30 \%)$ female patients. As mentioned before the minimum age was 18 year while the maximum age limit was 50 years with mean age of $28.4 \pm 8.1$ years. Figure shows the age group and gender distribution of all the patients where majority of the patients are of age group of 18-30 years. Tinnitus was the most common complaint present in $50(83.3 \%)$ patients while hearing loss was present in $17(28.3 \%)$ patients and vertigo in $14(23.3 \%)$ patients. The shortest time interval after the start of COVID symptoms and performing audiometry was 24 days and longest time interval was 40 days with a mean of 33.4 days ( \pm 2.1).

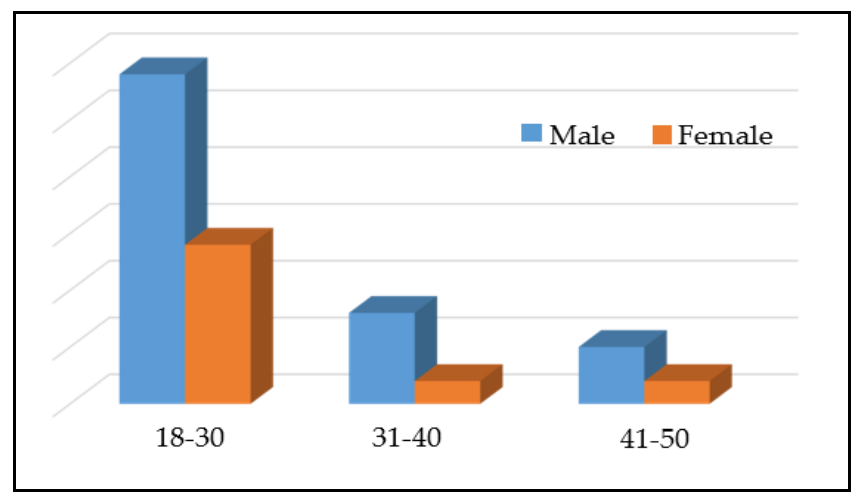

Figure: Gender and age group distribution $(n=60)$.

Table shows the overall results of puretone audiogram in both right and left ear in particular group of patients with one or more symptoms. Puretone audiogram was normal in right ear in $27(45 \%)$ patients and in left ear in $25(41.7 \%)$ patients and majority of the patients are those who had isolated complaint of tinnitus or vertigo only $(p=.000)$ (table). None of the patients with complaint of hearing loss had normal pure tone audiogram in either right or left ear $(p=0.000)$. Patients with all the threecomplaints had more hearing impairment where majority 
had moderate or severe hearing loss $(p=0.000)$. Similarly patients with complaint of both hearing loss and tinnitus had more hearing loss on puretone audio-gram, 12 patients with moderate or severe hearing loss in both ears $(p=0.000)$. All patients with isolated complaint of vertigo ( 9 patients) had normal audiogram in both ears $(p=0.000)$. tissues or may be related to vascular damage caused by hyper coagulability. Hypercoagulability state causes damage to inner ear apparatus as this is highly susceptible to ischemia. 'Cytokine storm' which is the result of excessive release of cytokine due to exaggerated host response in COVID-19 infection, is the cause for multi-organ failure including the inner

Table: Cross table relation of symptoms with hearing loss on PTA $(n=60)$

\begin{tabular}{|c|c|c|c|c|c|c|c|c|c|c|c|}
\hline \multirow[b]{2}{*}{ Complaints } & \multirow[b]{2}{*}{$\begin{array}{c}\text { Total } \\
\text { (n) }\end{array}$} & \multicolumn{5}{|c|}{ Pure Tone Audiogram Right } & \multicolumn{5}{|c|}{ Pure Tone Audiogram Left } \\
\hline & & $\begin{array}{c}\text { Normal } \\
<25 \mathrm{~dB}\end{array}$ & $\begin{array}{c}\text { Mild 26- } \\
40 \mathrm{Db}\end{array}$ & $\begin{array}{c}\text { Moderate } \\
41-70 \text { dB }\end{array}$ & $\begin{array}{c}\text { Severe } \\
>70 \mathrm{~dB}\end{array}$ & $\begin{array}{c}p- \\
\text { value }\end{array}$ & $\begin{array}{l}\text { Norma } \\
<25 \mathrm{~dB}\end{array}$ & $\begin{array}{r}\text { Mild } 26 \\
40 \mathrm{~dB}\end{array}$ & $\begin{array}{c}\text { Moderate } \\
41-70 \mathrm{~dB}\end{array}$ & $\begin{array}{l}\text { Severe } \\
>70 \mathrm{~dB}\end{array}$ & $\begin{array}{c}p \text { - } \\
\text { value }\end{array}$ \\
\hline $\begin{array}{l}\text { Hearing } \\
\text { Loss }\end{array}$ & 1 & - & - & 1 & - & \multirow{8}{*}{0.000} & - & - & 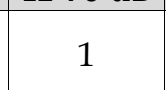 & 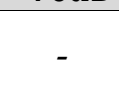 & \multirow{8}{*}{0.000} \\
\hline Tinnitus & 33 & 17 & 16 & - & - & & 14 & 19 & - & - & \\
\hline Vertigo & 9 & 9 & - & - & - & & 9 & - & - & - & \\
\hline $\begin{array}{l}\text { Hearing Loss } \\
+ \text { Tinnitus }\end{array}$ & 12 & - & - & 11 & 1 & & - & - & 11 & 1 & \\
\hline $\begin{array}{l}\text { Hearing Loss } \\
+ \text { Vertigo }\end{array}$ & 0 & - & - & - & - & & - & - & - & - & \\
\hline $\begin{array}{l}\text { Tinnitus + } \\
\text { Vertigo }\end{array}$ & 1 & 1 & - & - & - & & 1 & - & - & - & \\
\hline $\begin{array}{l}\text { Hearing Loss } \\
+ \text { Tinnitus } \\
+ \text { Vertigo }\end{array}$ & 4 & - & - & 1 & 3 & & - & 1 & 1 & 2 & \\
\hline Total & 60 & 27 & 16 & 13 & 4 & & 25 & 19 & 13 & 3 & \\
\hline
\end{tabular}

\section{DISCUSSION}

There are many infections of viral origin which could lead to deafness whether it may be of congenital or acquired in type or unilateral or bilateral. ${ }^{10}$ Some viruses could damage the inner ear directly but, some produce intense inflammatory reaction which in turn lead to the damage. Still some other viruses may boost vulnerability of the structures to bacterial and fungal infection, which in turn cause deafness. Isolated cases of sudden sensori-neural deafness in COVID-19 patients has been described in the literature. ${ }^{11}$ Characteristically, deafness induced by the viruses is mainly sensorineural, but either conductive or mixed deafness may sometimes follow. Recovery from the hearing loss may follow spontaneously. ${ }^{12,13}$ Viruses which are known to affect hearing includes measles, mumps, herpes simplex, hepatitis, HIV, rubella, enteroviruses and cytomegalovirus, but these are uncommonly seen as the cause of sensori- neural deafness. ${ }^{4}$ This could be the consequence of damage to the inner ear cells or may be because of effect on the auditory brainstem, resulting in tinnitus and equilibrium problems along with hearing issues. ${ }^{12}$ In case of COVID-19 infection, it is still unclear whether the auditory system is the target, although the virus has already been isolated with in middle ear and mastoid tissue. ${ }^{14}$ The effecton hearing may be due to a direct infection of neural ear..$^{15}$ Another possible mechanism for hearing loss in patients with corona virus infection may be ischemic infarct or hemorrhage in the brainstem or central cortex. In summary, different mechanism are involved in COVID-19 disease which can affect the inner ear including immune mediated damage, ischemic damage, haematogenous spread of the viruses and inflammation of auditory pathway. In addition, angiotensin converting enzyme receptors (ACE2) receptors are also present in the neurons and the glial cells, which is considered as the entry site for SARS-CoV2.16

This study was planned to measure and compare the pure tone audiometry findings in COVID-19 affected individuals, to enhance the emerging literature on early and delayed otologic manifestations of COVID-19. Sixty patients were enrolled in the present study with complaint of hearing loss, tinnitus or vertigo. Results of our study showed that the hearing impairment was present in $100 \%$ of the patients who are complaining of deafness and mild deafness was also observed in 16 patients in right ear and 19 patients in left ear in those patients who had only complaint of tinnitus with no hearing loss. Through this data, it can be demonstrated that lack of symptoms of deafness is not enough to rule out auditory involvement. Patients with conductive deafness due to pathology of the middle ear and Eustachiantube 
are excluded from this study. As observed from previous studies that corona virus is neuroinvasive in nature causing multiple peripheral neuropathies. Although, this research was conducted to point out relationship between COVID- 19 and hearing related complaints, it was also observed that there is association of deafness with other neurological symptoms like vertigo andtinnitus.

In our study, tinnitus was present in as asymptom in majority rather than hearing impairment. Among the 50 patients presenting complain was of tinnitus but only 16 patients complained of associated symptom of hearing loss. Mild hearing loss on pure tone audiogram was observed in majority of these patients with tinnitus only. It is much similar to other studies which shows tinnitus as a main symptom, not hearing loss in COVID infected patients presented with mild to moderate disease. ${ }^{1719}$ Awareness regarding sensorineural hearing loss is important because early and appropriate treatment will help to improve clinical outcome and will also reduce subsequent complications. Some researchers have established the key role of corticosteroids in the treatment of sudden sensorineural deafness and was used in COVID-19 patients showing complete recovery after one month treatment. ${ }^{20}$

In our study, high frequency sensory-neural loss was found in substantial number of COVID-19 positive patients, the deterioration effect may be due damage to outer hair cells of cochlea like other viruses which cause damage to auditory system, the mechanism of which is unknown. This high frequency SNHL was even detected in patients who have no symptom hearing loss and the available literature shows chances of COVID-19-related inner ear damage. This concludes that COVID-19 infection can results in destructive effects on function of the cochlear hair cell despite having no symptom. Whether this effect is reversible after some time or not, we do not know much, so further research is required regarding effects and mechanism of this damage. Hence, prompt detection of this loss is essential and appropriate intervention is immediately required to enhance better quality of life in thesepatients.

\section{CONCLUSION}

Involvement of the auditory system in COVID19 infection is being increasingly reported in the literature. Our study also shows that auditory and vestibular system involvement in reasonably common in COVID-19 patients. Tinnitus is the most frequent symptom and it should be investigated with full audiological investigations in every patient of corona virus infection even after recovery from the primary infection.

\section{ACKNOWLEDGEMENT}

We are deeply grateful to administration of Creek General Hospital for providing free audiolo-gical testing service support for this study.

\section{LIMITATION OF STUDY}

One of the limitation of this study is that we have only performed audiometric assessment in symptomatic patients with ear symptoms because of financial constraints. This is in agreement with another study done by Droret al concluding that large scale of hearing screening is suggested in asymptomatic patients recovered from COVID-19 infection. ${ }^{21}$ However, larger scale studies are required in this framework to clearly assess the demographic picture as well as possible etiological mechanism regarding association of auditory pathway with COVID-19 infection.

\section{Conflict of Interest: None}

\section{Author Contribution:}

SF: Manuscript writing, KM: Study design \& data analysis, IHU: Statistical analysis \& critical revision, SZ: Data collection, MI: Data collection, AM: Data collection.

\section{REFERENCES}

1. Guo YR, Cao QD, Hong ZS, Tan Y, Chen SD, Jin HJ, et al. The origin, transmission and clinical therapies on coronavirus disease 2019 (COVID-19) outbreak - an update on the status. Military Med Res 2020; 7: 11.

2. Karimi-Galougahi M, Naeini AS, Raad N, Mikaniki N, Ghorbani J. Vertigoand hearing loss during the COVID-19 pandemic - is there an association? Acta Otorhinolaryngol Ital 2020; 40(6): 463-5

3. Lechien JR, Chiesa-Estomba CM. Olfactory and gustatory dysfunctions as a clinical presentation of mild to moderate forms of the Coronavirus disease (COVID-19): a multicenter European study. Eur Arch Otorhinolaryngol 2020; 277(8): 2251-61

4. Cohen, BE. Viral causes of hearing loss: a review for hearing health professionals. Trends Hear 2014; 18: 1-17.

5. Fidan V. New type of corona virus induced acute otitis media in adult. Am J Otolaryngol 2020; 41(3): 102487.

6. National Institute for Health and Care Excellence. 2020. COVID-19 rapid guideline: managing the long-term effects of COVID-19. [Internet] https://www.nice.org.uk/guidance/ ng188/resources/covid19-rapid-guideline-managing-thelongterm-effects-of-covid19-pdf-66142028400325. Accessed 20 January 2021 [Google Scholar]

7. Adler SP. Congenital cytomegalovirus screening. Pediatr Infect Dis J 2005; 24(12):1105-6.

8. Sedaghat, Z, Karimi N. Guillain Barre syndrome associated with covid-19 infection: a case report. J Clin Neurosci 2020; 76: 233-235.

9. Li YC, Bai WZ, Hashikawa T. The neuroinvasive potential of SARS-CoV2 may play a role in the respiratory failure of COVID-19 patients. J Med Virol 2020; 92(6): 552-5.

10. Mustafa MWM. Audiological profile of asymptomatic COVID-19 PCR-positive cases. Am J Otolaryngol 2020; 41(3): 102483.

11. Sriwijitalai, W, Wiwanitkit V. Hearing loss and COVID-19: A Note. Am J Otolaryngol 2020; 102473.

12. Abramovich S, Prasher DK. Electrocochleography and brainstem potentials in Ramsay Hunt syndrome. Arch Otolaryngol Head Neck Surg 1986; 112(9): 925-8.

13. Al Muhaimeed H, Zakzouk SM. Hearing loss and herpes simplex. J Trop Pediatr 1997; 43(1): 20-4.

14. Frazier KM, Hooper JE, Mostafa HH, Stewart CM. SARS-CoV2 virus isolated from the mastoid and middle ear: implications 


\section{Audiometric Assessment in Post COVID-19 Patients}

for COVID-19 precautions during ear surgery. JAMA Otolaryngol. Neck Surg 2020; 146: 964e966.

15. Cui C, Yao Q, Zhang D, Zhao Y, Zhang K, Nisenbaum E, et al. Approaching otolaryngology patients during the COVID19 pandemic. Otolaryngol - Head Neck Surg 2020; 163(1): 121131.

16. Dharmarajan S, Bharathi MB, Sivapuram K, Prakash BG, Madhan S, Madhu1 A, Devi1 GN, Aliya SA, Ramya SB. Hearing loss - A camouflaged manifestation of COVID-19 infection. Indian J Otolaryngol Head Neck Surg 2021; 73(4): 1-5.;

17. Lechien JR, Chiesa-Estomba CM, Place S, Laethem YV, Caba$\operatorname{raux} \mathrm{P}$, Mat $\mathrm{Q}$, et al. Clinical and epidemiological characteristics of 1420 European patients with mild-to-moderate coronavirus disease. J Intern Med 2020; 288(3): 335-44.
18. Di Mauro, Scavone C, Rafaniello C, Rossi F, Capuano A. SARS-Cov-2 infection: Response of human immune system and possible implications for the rapid test and treatment. Int Immunopharmacol 2020; 84: 106519.

19. Maharaj S, Alvarez MB, Mungul S, Hari K. Otologic dysfunction in patients with COVID-19: a systematic review. Laryngoscope Investig Otolaryngol 2020; 5(6): 1192-1196.

20. Hara JH, Zhang JA, Gandhi KR, Flaherty A, Barber W, Leung MA, Burgess LP. Oral and intratympanic steroid therapy for idiopathic sudden sensorineural hearing loss. Laryngoscope Investig Otolaryngol 2018; 3: 73-7.

21. Dror AA, Karayanni NK, Oved A, Daoud A, Eisenbach N, Mizrachi $\mathrm{M}$, et al. Auditory performance in recovered SARSCOV-2 patients. Otol \& Neurotol 2021; 42(5): 660- 667. 